\title{
Correction to: X-ray beam properties available at the nuclear resonant scattering beamline at SPring-8
}

\section{Yoshitaka Yoda ${ }^{1}$}

Published online: 5 September 2019

(C) Springer Nature Switzerland AG 2019

\section{Correction to: Hyperfine Interactions (2019) 240:72 https://doi.org/10.1007/s10751-019-1598-3}

Due to technical constraints this article was published in volume 240:1 with erroneous article citation ID number 2 whereas this should have been $\mathbf{7 2}$ which is corrected as such. Springer Nature sincerely apologizes towards the author(s) for the inconvenience caused.

Publisher's note Springer Nature remains neutral with regard to jurisdictional claims in published maps and institutional affiliations.

This article is part of the Topical Collection on Proceedings of the International Conference on Hyperfine Interactions and thier Applications (HYPERFINE 2019), Goa, India, 10-15 February 2019

Edited by S. N. Mishra, P. L. Paulose and R. Palit

The online version of the original article can be found at https://oi.org/10.1007/s10751-019-1598-3

Yoshitaka Yoda

yoda@ spring8.or.jp

1 Research and Utilization Division, Japan Synchrotron Radiation Research Institute, Sayo-cho, Sayo-gun, Hyogo 679-5198, Japan 